\title{
Cellular Localization and Production of Lovastatin from Monascus purpureus
}

\author{
A. SEENIVASAN ${ }^{*}$, S. VENKATESAN ${ }^{1}$ AND TAPOBRATA PANDA ${ }^{1}$
}

Department of Biotechnology, National Institute of Technology Raipur, G. E. Road, Raipur-492 010, Chhattisgarh, ${ }^{1}$ Biochemical Engineering Laboratory, MSB 140A, Department of Chemical Engineering, Indian Institute of Technology Madras, Chennai-600036, India

Seenivasan, et al.: Studies on Biosynthesis of Lovastatin

Lovastatin is the first FDA-approved antihypercholesterolemic drug for the treatment of cardiovascular diseases. Monascus purpureus is one of the safest molds for the production of lovastatin that has been used in the preparation of Chinese medicine Red-yeast rice. This investigation dealt with the effect of both static and dynamic culture conditions on the morphological change and localization of lovastatin in Monascus purpureus. In dynamic culture condition, pellet morphology was observed and the maximum intra- and extra-cellular components of lovastatin including both $\beta$-hydroxy acid and lactone forms were 1043.45 and $207.94 \mu \mathrm{g} / \mathrm{l}$, respectively. Filamentous (mat) form of morphology was observed in the static culture condition and the intra- and extracellular concentration of lovastatin were 677.9 and $789.2 \mu \mathrm{g} / \mathrm{l}$, respectively. Taguchi's $L_{12}\left(11^{2}\right)$ orthogonal arrays was employed to find the optimal conditions for the submerged production of lovastatin and for the growth of Monascus purpureus. Three physical and five chemical variables were considered in the current experimental study. The maximum production of lovastatin was observed to be $3.66 \mathrm{mg} / \mathrm{l}$. Among the chemical parameters, $\mathrm{MnSO}_{4}$ and $\mathrm{MgSO}_{4}$ were the most significant parameters for the production of lovastatin. Physical parameters, viz., agitation rate and temperature, were also equally significant for the production of lovastatin. Ammonium chloride was the most significant parameter among the variables studied for the growth of Monascus purpureus, followed by glucose and phosphorous sources $\left(\mathrm{KH}_{2} \mathrm{PO}_{4}\right)$. Statistical analysis showed that those parameters were significant with more than $99 \%$ confidence $(\mathbf{p}<\mathbf{0 . 0 1 )}$.

Key words: HMG-CoA reductase inhibitor, Static and dynamic culture conditions, pellet and mycelial morphology, optimization

Hypercholesterolemia is the presence of high cholesterol level in the blood, which is commonly associated with coronary heart disease and other complications. Statins are currently prescribed as hypocholestermic drugs that reduce and control the blood cholesterol levels. Among statins, lovastatin $\left(\mathrm{C}_{24} \mathrm{H}_{36} \mathrm{O}_{5}\right.$, mevinolin, monacolin $\left.\mathrm{K}\right)$ was the first FDA-approved and commercialized antihypercholesterolemic drug ${ }^{[1]}$. It is a competitive inhibitor of $\beta$-hydroxy $\beta$-methylglutaryl-CoA (HMG$\mathrm{CoA})$ reductase, the enzyme that catalyses the rate limiting reaction of de novo pathway of cholesterol biosynthesis, which is responsible for producing twothirds of the body's daily requirement of cholesterol ${ }^{[1-5]}$. Lovastatin has served as a precursor for the next generation drugs, such as, wuxistatin and simvastatin and offered pleiotropic clinical applications ${ }^{[1,6-9]}$.
Several microorganisms, viz., Aspergillus sp., Monascus sp., Pleurotus sp., Phoma sp., Doratomyces nanus, and Gymnoascus umbrinus were found to produce lovastatin through fermentation route ${ }^{[1,10]}$. Among the organism, Monascus sp. has received more attention for the production of lovastatin due to its low production of cytotoxins (e.g. citrinin, a neurotoxins $)^{[11,12]}$. Monascus sp. (M. purpureus and M. ruber) has been employed in the preparation of Red-yeast rice (RYR), a traditional fermented food consumed in Asian countries as "red koji". Later, It was identified that lovastatin is

This is an open access article distributed under the terms of the Creative Commons Attribution-NonCommercial-ShareAlike 3.0 License, which allows others to remix, tweak, and build upon the work non-commercially, as long as the author is credited and the new creations are licensed under the identical terms

Accepted 18 November 2017

Revised 11 April 2017

Received 30 November 2016

Indian J Pharm Sci 2018;80(1):85-98 
a functional constituent of $\mathrm{RYR}^{[1,13-15]}$. Monascus sp. was also exploited for various metabolites, viz., $\gamma$-aminobutyric acid, pigments, lipids, and structural analogues of lovastatin (pravastatin, compactin, monacolin J $)^{[13,16-19]}$. Endo ${ }^{[20]}$ has first reported the production of lovastatin from Monascus sp. in 1979. Several studies has been reported on the optimization of lovastatin production from Monascus

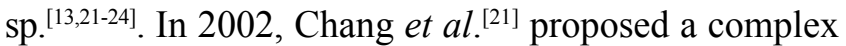
medium for $M$. ruber. The production of lovastatin was also carried out in solid-state fermentation by Panda et al. ${ }^{[25]}$ using a mixed culture of Monascus sp. Recent attempt on Monascus sp. showed that the possibility of the production of lovastatin without citrinin $^{[26,27]}$. Manzoni et al. ${ }^{[18]}$ have showed the production of pravastatin along with lovastatin in Monascus sp.

Lovastatin has two forms, hydroxy acid and lactone forms (fig. 1). However, these individual forms

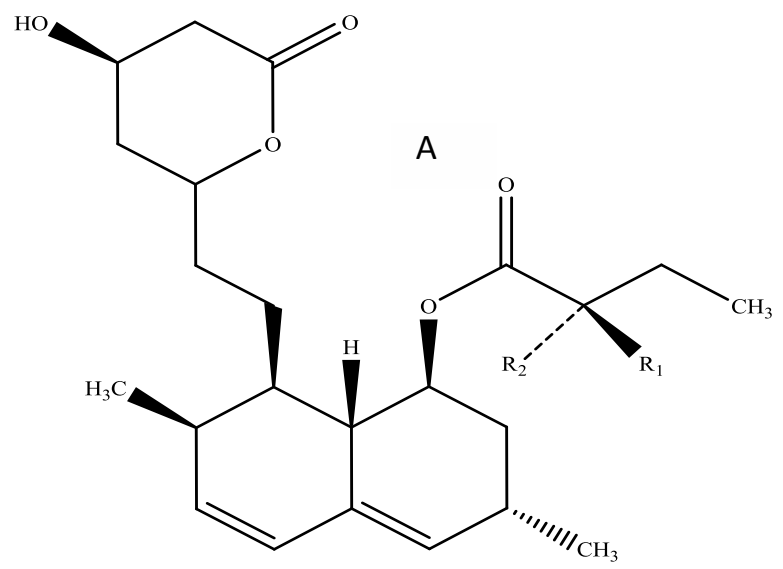

have different physico-chemical and pharmaceutical properties $^{[30]}$. It was stated that hydroxy acid form of lovastatin was sparingly soluble in water than lactone form and quite stable in the liquid medium ${ }^{[28]}$. Yang and Hwang ${ }^{[29]}$ studied the interconversion between hydroxy and lactone forms of lovastatin and reported the possible accumulation of undesired forms, such as, ester forms of lovastatin during the interconversion. Hence, the simultaneous determination of individual forms could result in the more accurate quantification of lovastatin that helps in the localization of lovastatin in the cell during the fermentation. Localization studies may help to select an appropriate downstream process as well as useful to perform an extractive fermentation and a tailor-made synthesis of lovastatin analogues, i.e., simvastatin ${ }^{[7]}$. To the best of our knowledge, it is the first attempt to detail the localization of lovastatin content in M. purpureus grown under both static (nonagitated) and dynamic culture (agitated) conditions.

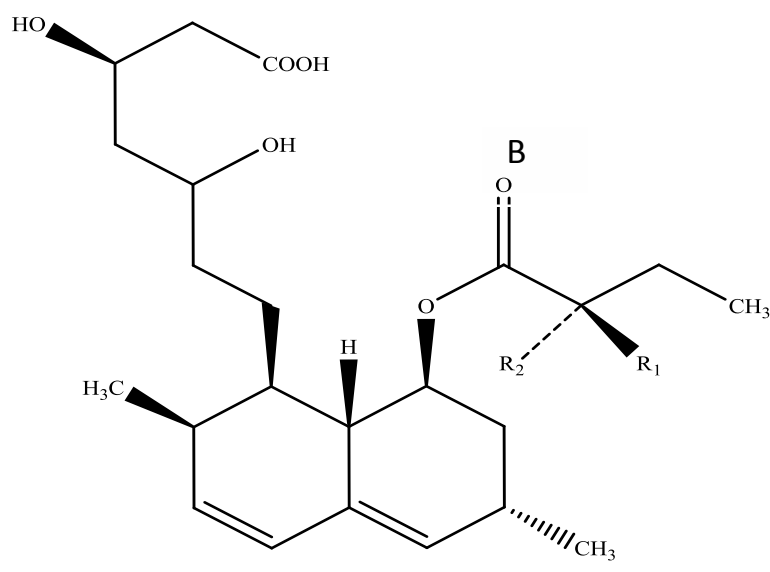

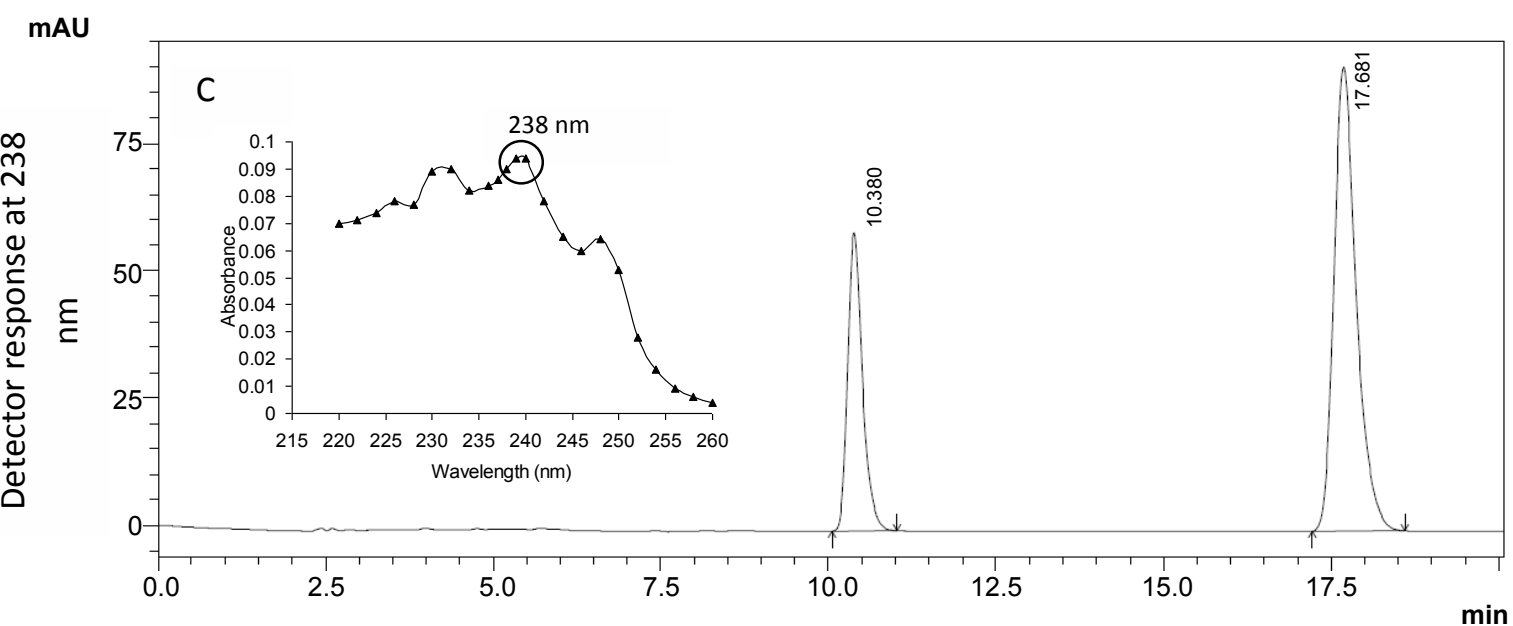

Fig. 1: Proactive lactone (closed ring) (A), active hydroxy acid (open ring) forms of lovastatin (B) and HPLC-PDA chromatogram of hydroxy acid and lactone forms of lovastatin (C)

$R_{1}$ and $R_{2}$ are the functional groups present on butyric side chain and the functional groups of $R_{1}$ and $R_{2}$ are $-O H$ and $-C_{3}$ for lovastatin, respectively (A, B). Conditions employed: isocratic elution with acetonitrile and $0.1 \%$ phosphoric acid (60:40, v/v), flow rate at $1 \mathrm{ml} / \mathrm{min}$ and column temperature $40^{\circ}$, injection volume is $20 \mu \mathrm{l}$. The retention time of hydroxy form and lactone ring structure are $10.38 \mathrm{~min}$ and $17.68 \mathrm{~min}$, respectively. The inner diagram showed the maximum absorbance $\left(\lambda_{\max }\right)$ of lovastatin at 238 $\mathrm{nm}$ read in spectrophotometer for the range between $220 \mathrm{~nm}$ and $260 \mathrm{~nm}(C)$ 
Suitable statistical and/or non-statistical tools were employed to design the experiments and analysis the data for the optimization experiments ${ }^{[30-32]}$. The conventional method of studying one variable at a time was very inefficient in many cases, costly, and labour intensive ${ }^{[31-33]}$. Statistical methods were famous in the field of optimization of fermentation processes ${ }^{[31]}$. Among statistical experimental designs, Taguchi's method has been widely used in industrial process design, principally in the developmental trials. This technique could generate enough process information to establish screening and optimal condition with a minimum number of experiments ${ }^{[34]}$. To nullify the impact of uncontrolled (noise) factors, Taguchi has developed an orthogonal array technique, a robust and well-established engineering technique, to improve the quality or quantity of product by making it robust/ insensitive to noise factors ${ }^{[33,35]}$. As a process using a single trial with a few experiments, Taguchi's method was used successfully to optimize the production of many fermentation-derived products, viz., sucrose monoester, griseofluvin, ethanol and biomass ${ }^{[36-39]}$. Another advantage of this method is to study the effect of both physical and chemical parameters on the desired product in a single experimental design.

The objective of the present study was to determine the localization of individual forms of lovastatin in M. purpureus grown in both static and dynamic culture conditions separately and to determine the optimal conditions for the production of lovastatin and biomass of Monascus purpureus using Taguchi's orthogonal array method.

\section{MATERIALS AND METHODS}

Mevinolin (lovastatin) was procured from Sigma Aldrich, St. Louis, MO, USA. All other chemicals were of analytical grade and procured from Sisco Research Laboratories Pvt. Ltd., Mumbai, India. The preparation of individual forms (hydroxy- and lactone forms) of lovastatin and standard chart preparation were described in detail in our previous paper ${ }^{[40]}$. M. purpureus MTCC 369 was obtained from the Institute of Microbial Technology, Chandigarh, India. The organism was maintained on potato-dextrose-agar slants $^{[13]}$. The organism was sub-cultured for every $30 \mathrm{~d}$ of time interval. The slant cultures were grown at $30 \pm 2^{\circ}$ and stored at $4 \pm 1^{\circ}$ until further use.

\section{Culture conditions:}

The seed medium for the growth of the organism was described by Su et al..$^{[13]}$ and has the composition (g/l): glucose- 100; peptone- 10; $\mathrm{KNO}_{3}-2 ; \mathrm{NH}_{4}\left(\mathrm{H}_{2} \mathrm{PO}_{4}\right)-2$; $\mathrm{MgSO}_{4} \cdot 7 \mathrm{H}_{2} \mathrm{O}-0.5 ; \mathrm{CaCl}_{2}-0.2$. The initial $\mathrm{pH}$ of the seed medium was adjusted to 6 using $2 \mathrm{M} \mathrm{NaOH}$. One hundred millilitres of sterile seed medium contained in a 500-ml Erlenmeyer flask was inoculated with $1 \mathrm{ml}$ of spore suspension containing $10^{5}$ to $10^{6}$ (spores) and incubated in a temperature controlled rotary shaker maintained at $140 \mathrm{rev} / \mathrm{min}$ and $30 \pm 1^{\circ}$ for a period of $48 \mathrm{~h}$.

The production medium had the following composition (g/l): dextrose- 29.59; ammonium chloride $\left(\mathrm{NH}_{4} \mathrm{Cl}\right)$ 3.86; potassium dihydrogen orthophosphate $\left(\mathrm{KH}_{2} \mathrm{PO}_{4}\right)$ 1.73; $\mathrm{MgSO}_{4} \cdot 7 \mathrm{H}_{2} \mathrm{O}-0.86 ; \mathrm{MnSO}_{4} \cdot \mathrm{H}_{2} \mathrm{O}-0.19 ; \mathrm{pH}^{[22]}$. A 500-ml Erlenmeyer flask containing $100 \mathrm{ml}$ of media was inoculated with $10 \%(\mathrm{v} / \mathrm{v})$ seed culture (dry weight of cell was $2 \pm 0.2 \mathrm{~g} / \mathrm{l})$ and incubated at $30^{\circ}$ for $14 \mathrm{~d}$.

\section{Extraction of lovastatin:}

About $5 \mathrm{ml}$ of culture sample was harvested from 14 d old fermentation broth. Samples were homogenized by ultrasonication at $20 \mathrm{kHz}$ for 20 min having pulse rate of $3 \mathrm{~s}$. The homogenized fermentation broths were extracted with an equal volume of ethyl acetate at $60^{\circ}$ for $30 \mathrm{~min}$ with intermittent shaking ${ }^{[00]}$. The upper organic layers were separated from the aqueous layers by centrifugation at $4000 \mathrm{rpm}$ for $20 \mathrm{~min}$ to settle the debris of cells. The clear organic phases (ethyl acetate) were dried under vacuum conditions in a rotary evaporator at $50^{\circ}$. The resultant residues were further dried under vacuum for an hour to remove the residual moisture and solvents. Finally, the dried residues were re-suspended in pure acetonitrile. This suspension was filtered through a $0.45 \mu \mathrm{m}$ filter paper. The filtered samples were analysed by high-performance liquid chromatography (HPLC).

\section{Quantification of lovastatin and glucose:}

An analytical HPLC system was employed on a gradient mode (Shimadzu, Prominence HPLC, Kyoto, Japan), equipped with a photodiode array detector (PDA) and a Luna $\mathrm{C} 18$ column (Phenomenex ${ }^{\circledR}$ ). The mobile phase composed of acetonitrile and acidified water $(0.1$ $\% \mathrm{H}_{3} \mathrm{PO}_{4} ; 60: 40, \mathrm{v} / \mathrm{v}$ ) was filtered through a $0.22-\mu \mathrm{m}$ membrane filter and degassed in an ultrasonic bath. The flow rate and column temperature were maintained at $1 \mathrm{ml} / \mathrm{min}$ and $40^{\circ}$, respectively. The sample injection volume was $20 \mu$. The working standards of lactone and hydroxy acid forms of both lovastatin were analysed by HPLC-PDA at $238 \mathrm{~nm}$ (fig. 1) ${ }^{[40]}$.

Glucose was assayed using refractive index detector 
(RID) in HPLC. The aminex HPX-87H column $\left(300 \times 7.8 \mathrm{~mm}\right.$, i.d; Bio-Rad $\left.{ }^{\mathbb{R}}\right)$ was used with the mobile phase composition of $5 \mathrm{mM} \mathrm{H}_{2} \mathrm{SO}_{4}$ and the oven temperature and flow rate were maintained at $50^{\circ}$ and $0.5 \mathrm{ml} / \mathrm{min}$. The cell free broth was centrifuged to settle the suspended particle followed by filtration with $0.45 \mu \mathrm{m}$ nylon membrane to analyses the residual concentration of glucose along the fermentation period.

\section{Estimation of biomass:}

For the estimation of dry cell weight, a $5 \mathrm{ml}$ aliquot of fermentation broth was collected from $14 \mathrm{~d}$ old fermentation broths and centrifuged aseptically at $4000 \mathrm{rpm}$ for $30 \mathrm{~min}$ to separate the cell mass. The residue containing the cell mass was washed repeatedly with distilled water, followed by centrifugation until complete washout of residual medium. Later, it was dried in a hot air oven at $70^{\circ}$ for $12 \mathrm{~h}$. Before measuring the dry weight of cell, it was brought to room temperature in vacuum desiccators. The effectiveness of the drying was confirmed by measuring the dry weight at a constant interval of time until it showed concordant values.

\section{Effect of culture condition on localization studies:}

To study the effect of culture condition on the localization of lovastatin, the production medium was prepared and separately cultured in both static (without agitation) and in dynamic (agitation) culture conditions. Static cultures were incubated at $30^{\circ}$ for $14 \mathrm{~d}$ on a rotary shaker without shaking and an equivalent set of liquid cultures were maintained at aforementioned condition on a rotary shaker at $120 \mathrm{rpm}$.

For localization studies, an aliquot of $10 \mathrm{ml}$ of the fermentation broth was collected aseptically and centrifuged at $5000 \mathrm{rpm}$ for $20 \mathrm{~min}$ to separate cells from fermentation broth. The clear supernatant containing extracellular lovastatin was extracted with equal volume of ethyl acetate. Cells were suspended in saline and centrifuged twice to remove the medium residues. The cell suspension was sonicated in ethyl acetate as the extracting solvent in the ratio of $1: 5(\mathrm{w} / \mathrm{v})$ to extract the intracellular lovastatin. The condition of extraction and quantification has been discussed in the previous paragraphs.

\section{Taguchi's orthogonal array:}

Taguchi postulates two parameters as input of any process; one is measurable (controlled) factor and simple to control; another one is noise factors (uncontrolled factors), which is difficult to control. Taguchi has developed a technique, called cross orthogonal arrays, where an orthogonal array of control variables (inner array) is crossed with an orthogonal array of noise variables (in outer array). For each setting of controlled variables, there will be " $n$ " runs in the noise variables from the outer array ${ }^{[35]}$. In the orthogonal array, each levels of a control variable are appears equals number of times in each columns, which helps to represent the relative effect of a level of the controlled variables over other levels and from the effect of other variables. This orthogonal array also reduces the experimental runs without compromising the pair wise balancing property ${ }^{[32,33,41]}$. More importantly, the findings are robust and are insensitive to variations, such as, variation between batches and unknown variations.

Taguchi has also introduced the term called signalto-noise ratio (performance criteria or loss function) that account the mean and variation in the process. There are three ways to represent the signal to noise ratio as follows: the larger, the better: $(S / N)_{i}=-10 \log$ $\left[1 / n \times \sum_{\mathrm{i}=\mathrm{n}}^{\mathrm{n}} \times 1 / \mathrm{y}_{\mathrm{i}}^{2}\right]$; maximizing the response; the smaller, the better: $(S / N)_{i}=-10 \log \left[1 / n \times \sum_{\mathrm{i}=\mathrm{n}}^{\mathrm{n}} \times \mathrm{y}_{\mathrm{i}}^{2}\right]$; minimizing the response; target is the best: $(S / N)_{\mathrm{i}}=-10 \log \left[s^{2} / \bar{y}^{2}\right]$; achieving the target value, where, $(S / N)_{\mathrm{i}}$ is the signal to noise ratio of $i^{\text {th }}$ run or experiment in the design, $y_{i}$, $\bar{y}, \mathrm{~s}$, and $\mathrm{n}$ are the response of ith experiment, mean response, standard deviation of the response and total number of experiment..

\section{Optimization methodology:}

According to Taguchi's orthogonal array, eight variables, including five chemical parameters and three physical parameters, in twelve experiments were used to evaluate the influence of various parameters on the production of lovastatin by M. purpureus MTCC 369 (Table 1). Experiments were performed according to an experimental plan given in Table 1. JMP 5.1.1 statistical software (SAS Institute Inc., Cary, North Carolina, USA) was used for this investigation. The selected $\mathrm{L}_{12}\left(11^{2}\right)$ orthogonal arrays (Table 1 ), in which, 2 levels of 8 columns (controlled factors) and 3 columns (dummy) are available within the orthogonal array.

Among the different chemical parameters studied, the following parameters such as, glucose, $\mathrm{NH}_{4} \mathrm{Cl}, \mathrm{KH}_{2} \mathrm{PO}_{4}$, magnesium sulphate $\left(\mathrm{MgSO}_{4}\right)$, and manganese sulphate $\left(\mathrm{MnSO}_{4}\right)$, have showed significant influence on the production of lovastatin ${ }^{[13,22]}$. Hence, these parameters have been examined along with physical parameters, such as, temperature, $\mathrm{pH}$ and agitation speed as shown in the Table 1. 


\section{RESULTS AND DISCUSSION}

There was a considerable difference in the morphology, substrate consumption, and localization of lovastatin by the organism when the culture conditions were varied between static and dynamic culture conditions. The rate of utilization of glucose was high in the

TABLE 1: $L_{12}\left(11^{2}\right)$ ORTHOGONAL ARRAY OF TAGUCHI'S EXPERIMENTAL DESIGN FOR PRODUCTION OF LOVASTATIN AND BIOMASS BY M. PURPUREUS MTCC 369

\begin{tabular}{|c|c|c|c|c|c|c|c|c|c|c|c|c|c|}
\hline $\begin{array}{l}\text { Run } \\
\text { no. }\end{array}$ & $\begin{array}{c}\text { Glucose } \\
(\mathrm{g} / \mathrm{l})\end{array}$ & $\begin{array}{c}\mathrm{NH}_{4} \mathrm{Cl} \\
(\mathrm{g} / \mathrm{l})\end{array}$ & $\begin{array}{c}\mathrm{KH}_{2} \mathrm{PO}_{4} \\
(\mathrm{~g} / \mathrm{l})\end{array}$ & $\begin{array}{c}\mathrm{MgSO}_{4} \\
(\mathrm{~g} / \mathrm{l})\end{array}$ & $\begin{array}{l}\mathrm{MnSO}_{4} \\
(\mathrm{~g} / \mathrm{l})\end{array}$ & $\begin{array}{c}\mathrm{pH} \\
\text { (Initial) }\end{array}$ & $\begin{array}{c}\text { Agitation } \\
\text { (rpm) }\end{array}$ & $\begin{array}{l}\text { Temp } \\
\text { ature }\end{array}$ & & $\begin{array}{c}\text { Bio- } \\
\text { mass } \\
(\mathrm{g} / \mathrm{l})\end{array}$ & $\begin{array}{c}\mathrm{S} / \mathrm{N} \\
\text { ratio for } \\
\text { biomass }\end{array}$ & $\begin{array}{l}\text { Lova- } \\
\text { statin } \\
(\mathrm{mg} / \mathrm{l})\end{array}$ & $\begin{array}{c}\mathrm{S} / \mathrm{N} \\
\text { ratio for } \\
\text { lovastatin }\end{array}$ \\
\hline 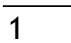 & $1(=5)$ & $(=1)$ & $(=1)$ & 98) & $0)$ & $=3)$ & 0) & $=25)$ & 111 & 6.02 & 15.6 & 1.69 & 4.56 \\
\hline & 5) & $1(=1)$ & $1(=1)$ & $1(=0.098)$ & $1(=0)$ & =6) & 50) & 35) & 222 & 6.36 & 16.07 & 1.14 & 1.14 \\
\hline & 5) & $1(=1)$ & $2(=4)$ & $(=0.98)$ & $2(=0.447)$ & $1(=3)$ & 0) & 25) & 222 & 8.27 & 18 & 56 & 11.03 \\
\hline & 5) & $2(=5)$ & $1(=1)$ & $2(=$ & $2(=$ & $1(=3)$ & 50) & 35) & 112 & 11.04 & 20 & 0.24 & -12.4 \\
\hline & 5) & $2(=5)$ & $2(=4)$ & $1(=0.098)$ & $2(=0$ & $2(=6)$ & 0) & 35) & 121 & 12.46 & 21.91 & 1.58 & 3.97 \\
\hline 0 & $1(=5)$ & $2(=5)$ & $2(=4)$ & 2( & $1(=0)$ & $2(=6)$ & 0) & 25) & 211 & 18.78 & 25.47 & 0.19 & -14.43 \\
\hline & $2(=40)$ & $1(=1)$ & $2(=4)$ & $2(=0.98)$ & $1(=0)$ & $1(=3)$ & 2( & 35) & 121 & 15.16 & 23.61 & 0.26 & -11.7 \\
\hline 8 & $2(=40)$ & $1(=1)$ & $2(=4)$ & $1(=0.098)$ & $2(=0.447)$ & $2(=6)$ & 2 (=150) & 1 (=25) & 112 & 15.18 & 23.63 & 3.66 & 11.26 \\
\hline 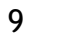 & $2(=40)$ & $1(=1)$ & $1(=1)$ & $2(=0.98)$ & $2(=0.447)$ & $2(=6)$ & 1 (=110) & $2(=35)$ & 211 & 4.98 & 13.95 & 1.48 & 3.4 \\
\hline 10 & $2(=40)$ & $2(=5)$ & $2(=4)$ & $1(=0.098)$ & $1(=0)$ & $1(=3)$ & $1(=110)$ & $2(=35)$ & 212 & 20.95 & 26.42 & 2.31 & 7.27 \\
\hline 11 & $2(=40)$ & $2(=5)$ & $1(=1)$ & $2(=0.98)$ & $1(=0)$ & $2(=6)$ & $1(=110)$ & 1 (=25) & 122 & 19.4 & 25.76 & 1.3 & 2.28 \\
\hline 12 & $2(=40)$ & $2(=5)$ & $1(=1)$ & $1(=0.098)$ & $2(=0.447)$ & $1(=3)$ & $2(=150)$ & 1 (=25) & 221 & 16.28 & 24.23 & 1.48 & 3.4 \\
\hline
\end{tabular}

Taguchi's experimental design included five components of medium constituent and three physiochemical parameters as factors with their corresponding production levels of lovastatin and biomass by M. purpureus MTCC 369
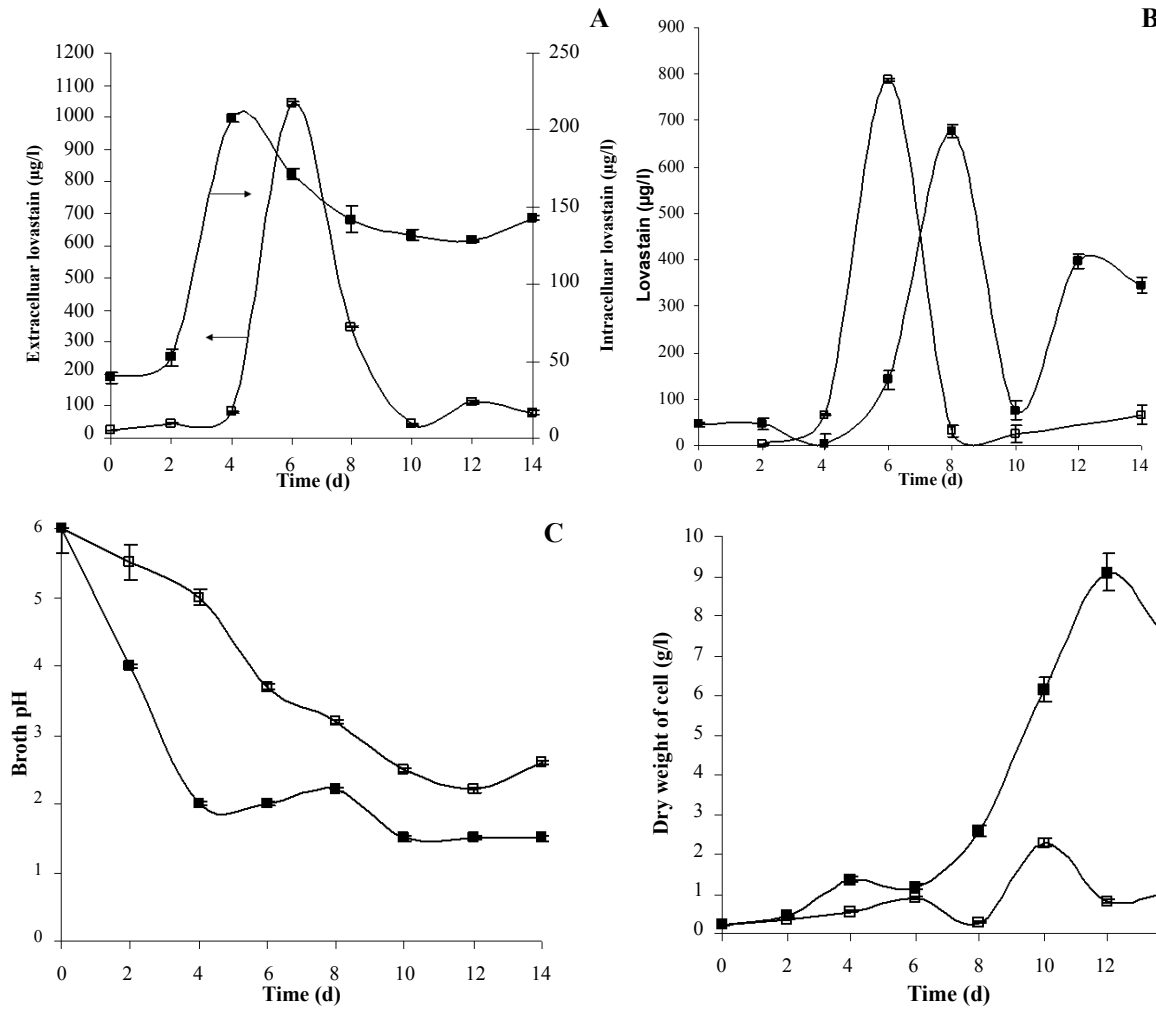

C

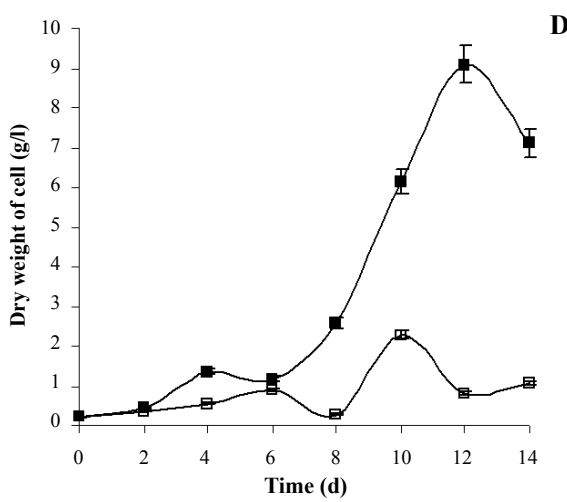

Fig. 2: The effect of culture conditions on the localization of lovastatin, and profiles of cell mass and pH of fermentation broth Localization of lovastatin in Monascus purpureus in both dynamic (A) and static culture (B) conditions. (C) The pH profile of the M. purpureus fermented broth and dry weight of the cell (D). The ligand (- $\square-)$ and (- - -) indicates the extracellular lovastatin and intracellular lovastatin, respectively (A and B). The ligand (- $\square-)$ and (- -$)$ indicates static and dynamic culture conditions, respectively (C and D) 


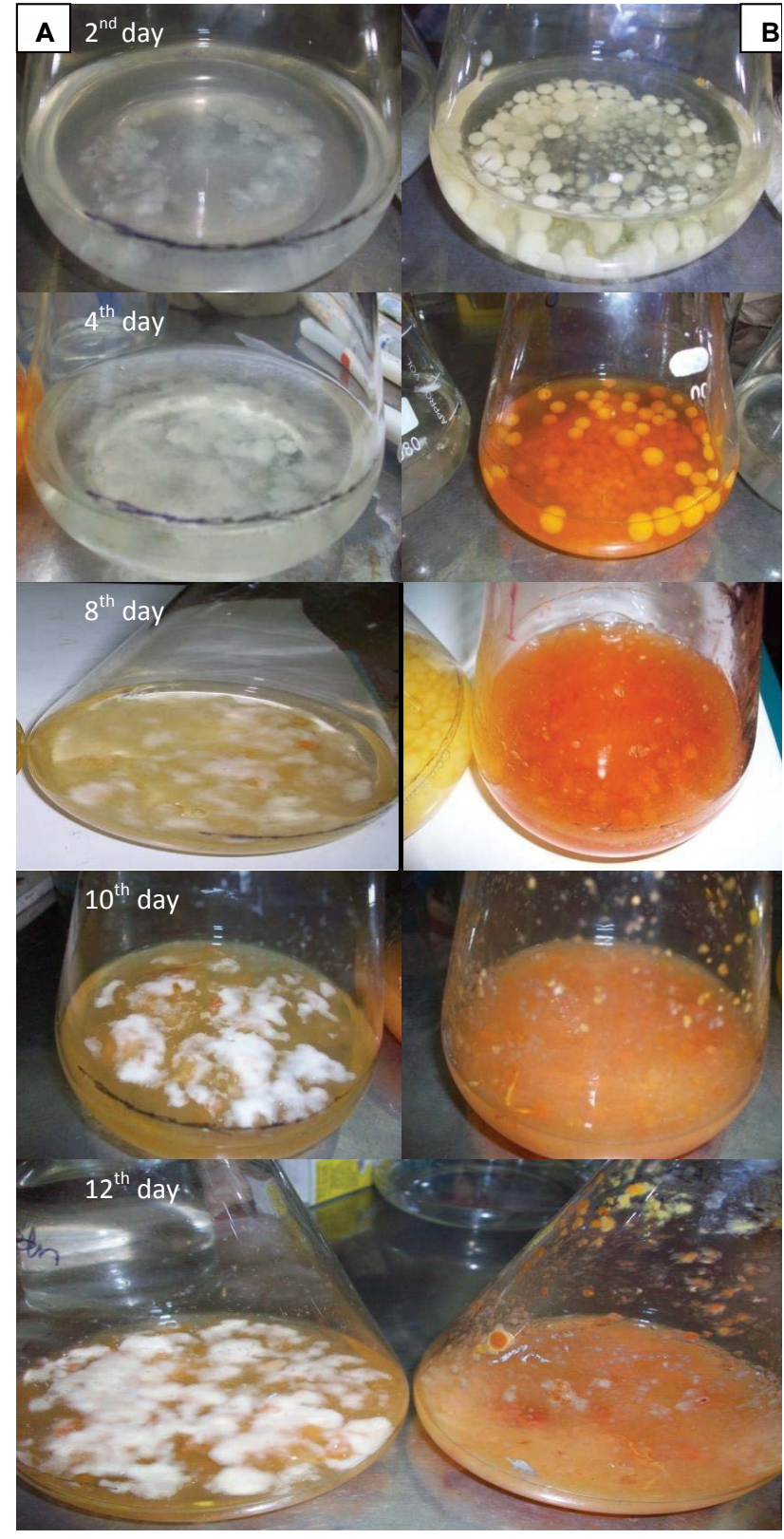

Fig. 3: Morphological observation of Monascus purpureus grew in both surface (A) and submerged (B) fermentations The pelleted and filamentous growth was observed in submerged and surface fermentation, respectively along the fermentation period of $14 \mathrm{~d}$

$8^{\text {th }} \mathrm{d}$ of fermentation. The maximum dry weight of the cell was observed as $9.08 \mathrm{~g} / 1$ in the dynamic culture condition (fig. 2). The apparent specific growth rate was $0.14 \mathrm{~h}^{-1}$ for the initial glucose concentration of $30 \mathrm{~g} / \mathrm{l}$ in the dynamic culture condition. Similarly, the specific growth rate of Monascus sp. was reported as $0.107 \mathrm{~h}^{-1}$ at the initial glucose concentration of $20 \mathrm{~g} / 1$ in a dynamic culture condition ${ }^{[17]}$. Similarly, Hamdi et al. ${ }^{[42]}$ found the specific growth rate of $M$. purpureus to be between 0.05 and $0.1 \mathrm{~h}^{-1}$. Musaalbakri et al. ${ }^{[43]}$ has reported the maximum specific growth rate as $0.055 \mathrm{~h}^{-1}$.
In static culture condition, surface (filamentous) growth morphology was observed throughout the fermentation process with the apparent specific growth rate of $0.065 \mathrm{~h}^{-1}$ and there was no cell disintegration in the static culture condition. The thickness and density of the filamentous morphology had increased along the fermentation period (fig. 3). Under the static culture conditions, the value of $\mathrm{pH}$ dropped gradually from 6 to $\sim 3$ over the entire fermentation period of $14 \mathrm{~d}$. The maximum cell concentration of $2.28 \mathrm{~g} / 1$ was observed in static culture (fig. 2).

There was considerable difference in the localization pattern of lovastatin in the dynamic culture condition compared to the static culture condition. The production of hydroxy acid and lactone was maximum in intracellular (5 fold higher) and extracellular (19 fold higher) compartment in the agitated or dynamic culture, respectively. From the present study, it has been observed that the interconversion between the hydroxy acid and lactone form of lovastatin was influenced by the $\mathrm{pH}$ of the fermentation period, which could be one of the reasons for its maximum accumulation of lactone form of lovastatin outside the cell than its hydroxy acid form. Since, the hydroxy acid form was converted into lactone form and other intermediates (monacolins) when the system $\mathrm{pH}$ was less than three or under acidic conditions $^{[44,45]}$.

In the dynamic culture condition, the maximum extracellular lovastatin content was found to be $1043.56 \mu \mathrm{g} / \mathrm{l}$ and the maximum intracellular content of lovastatin was $207.94 \mu \mathrm{g} / \mathrm{l}$ (fig. 2). The maximum extracellular localization of lovastatin could be due to easy mass transfer of lovastatin through the cell in dynamic (agitated) culture condition. The initial rate of formation of extracellular lovastatin was found to be $222.41 \mu \mathrm{g} / \mathrm{l} / \mathrm{d}$ in the dynamic culture condition. The maximum yield $\left(\mathrm{Y}_{\mathrm{P} / \mathrm{X}}\right)$ of lovastatin was found to be $1.45 \mathrm{mg} / \mathrm{g}$ of biomass (Table 2).

Another reason for the maximum extracellular localization of lovastatin was due to the cell lysis (pellet degradation) in the final days of fermentation (fig. 3). In the meantime, cells have maintained a steady state lovastatin profile inside the cell. Cells have reached their maximum holding capacity of lovastatin (i.e. $\sim 200 \mu \mathrm{g} / \mathrm{l}$ ) after $4 \mathrm{~d}$ of fermentation (fig. 2). A slight decrease in this concentration of intracellular lovastatin could be due to the cell lysis. It was observed that lovastatin could itself restrict its own production as it is shown in Aspergillus sp., would be the probable 
reason for its holding limits ${ }^{[46]}$. The amount of lactone form of lovastatin was found more than that of hydroxy acid form (26 fold higher) in the extracellular portion of static culture, whereas, the localization of hydroxy acid form was more than the lactone form ( 6 fold higher) within the cell.

In static culture of $M$. purpureus, the maximum extracellular localization of lovastatin was observed to be $789.2 \mu \mathrm{g} / 1$, whereas, the maximum intracellular content of lovastatin was $677.90 \mu \mathrm{g} / \mathrm{l}$ (fig. 2). The initial rate of the extracellular production of lovastatin was $214.2 \mu \mathrm{g} / 1 / \mathrm{d}$ (Table 2). Similarly, the initial rate of intracellular production of lovastatin was $85.7 \mu \mathrm{g} / \mathrm{l} / \mathrm{d}$. The maximum yield of lovastatin in the static culture condition was observed to be $1.39 \mathrm{mg} / \mathrm{g}$ of biomass.

In static culture condition, the concentration of intracellular localization of lovastatin was comparable to the extracellular content of lovastatin and it was high as compared to the intracellular content of lovastatin in the dynamic culture. It corroborated the significance of agitation on the localization of lovastatin in M. purpureus. Cells could easily find the substrate and release the product in the dynamic culture condition, whereas, in the surface culture, the mass transfer resistance limits the overall yield of lovastatin.

There was a variation in the profile of lovastatin, which could be due to the $\mathrm{pH}$ of the fermentation broth and medium complexity. At low $\mathrm{pH}$, the conversion between the individual forms of lovastatin and its analogues were random ${ }^{[44,45]}$, which brings variation in the profile of lovastatin.

On comparing the production of lovastatin in the static and dynamic culture conditions, it could be seen that the production of total lovastatin (sum of both intra and extracellular) in both culture has not been significantly varied. However, the extracellular localization of lovastatin was high in the dynamic culture compared to static culture, which could help lovastatin to be extracted easily from broth. The extraction of lovastatin from intracellular portion of cell complicates the downstream processing due to the presence of the structural analogues and intermediates of lovastatin ${ }^{[47]}$. It is very difficult to separate them from lovastatin that would increase the overall production cost.

Submerged batch fermentation studies were carried out for the production of lovastatin by Monascus purpureus using Taguchi's design of experiment (Table 1). The experimental results showed a significant variation in the production of lovastatin (Table 3 and fig. 4A). Maximum production of lovastatin was $3.66 \mathrm{mg} / \mathrm{l}$ for the condition using the experimental run number 8 (Table 1). Minimum production of lovastatin was $0.19 \mathrm{mg} / \mathrm{l}$ obtained using condition of run 6 . There is no difference in the production of lovastatin using conditions of either the run 9 or the run 12. Maximum production of lovastatin was obtained using the medium, whose composition was ( $\mathrm{g} / \mathrm{l})$ : glucose- 40 ; $\mathrm{NH}_{4} \mathrm{Cl}-1 ; \mathrm{KH}_{2} \mathrm{PO}_{4}-4 ; \mathrm{MgSO}_{4}^{-}$0.098; $\mathrm{MnSO}_{4}-0.447$ (Table 1).

From Table 3 and main effect plot for signal-tonoise ratio (fig. 4A), it can be observed that the parameters, viz., $\mathrm{NH}_{4} \mathrm{Cl}$ (at lower level), $\mathrm{KH}_{2} \mathrm{PO}_{4}$ (at higher level), $\mathrm{MnSO}_{4}$ (at higher level), and $\mathrm{MgSO}_{4}$ (at lower level) had significantly contributed to the production of lovastatin (Table 3 and fig. 4A). Glucose was relatively insignificant for the production of lovastatin compared to other parameters. The glucose is significant for the growth of cell than the production of secondary metabolites, lovastatin, may be due to the effect of catabolic repression. $\mathrm{NH}_{4} \mathrm{Cl}$ was one of the least significant variables for the production of lovastatin at its lower level, whereas, the same have shown significant influence on the growth of $M$. purpureus at its higher level. It showed that the limitation of nitrogen has enhanced the production of secondary metabolite, lovastatin. Main effect plot for the production of lovastatin showed the influence of individual parameters (fig. 4A).

Among the physical parameters, agitation speed and

TABLE 2: LOCALIZATION OF MAXIMUM CONCENTRATION OF LOVASTATIN IN BOTH STATIC AND DYNAMIC CULTURES OF M. PURPUREUS WITH YIELD CO-EFFICIENTS

\begin{tabular}{|c|c|c|c|c|c|c|c|}
\hline Condition & Fraction & $\begin{array}{c}\text { Max. product conc. } \\
(\mu \mathrm{g} / \mathrm{l})\end{array}$ & $\begin{array}{l}\text { DWC } \\
(\mathrm{g} / \mathrm{l})\end{array}$ & $\begin{array}{c}\text { Initial rate } \\
(\mu g / / / \text { day })\end{array}$ & $\begin{array}{c}\text { Max. } \\
Y_{X / S}(g / g)\end{array}$ & $\begin{array}{c}\text { Max. } \\
Y_{\mathrm{P} / \mathrm{X}}(\mathrm{mg} / \mathrm{g})\end{array}$ & $\begin{array}{c}\text { Max. } Y_{P / S} \\
(\mathrm{mg} / \mathrm{g})\end{array}$ \\
\hline \multirow{2}{*}{ Static culture } & Extracellular & $789.20\left(6^{\text {th }}\right)^{*}$ & $2.28\left(10^{\text {th }}\right)^{*}$ & 214.2 & \multirow{2}{*}{0.11} & \multirow{2}{*}{1.39} & \multirow{2}{*}{0.060} \\
\hline & Intracellular & $677.90\left(8^{\text {th }}\right)^{*}$ & & 85.7 & & & \\
\hline \multirow{2}{*}{$\begin{array}{l}\text { Dynamic } \\
\text { culture }\end{array}$} & Extracellular & $1043.45\left(6^{\text {th }}\right)^{*}$ & \multirow{2}{*}{$9.08\left(12^{\text {th }}\right)^{*}$} & 222.41 & \multirow{2}{*}{0.29} & \multirow{2}{*}{1.45} & \multirow{2}{*}{0.040} \\
\hline & Intracellular & $207.94\left(4^{\text {th }}\right)^{*}$ & & 47.17 & & & \\
\hline
\end{tabular}

*indicates the corresponding day for the maximum concentration of lovastatin and dry weight of the cell (DCW), where $\mu_{\text {app }}$ is the apparent specific growth rate $\left(\mathrm{h}^{-1}\right)$ 
TABLE 3: ANALYSIS OF THE DATA FOR DETERMINATION OF INFLUENCING FACTORS ON THE PRODUCTION OF LOVASTATIN AND BIOMASS

\begin{tabular}{|c|c|c|c|c|c|c|c|c|c|c|}
\hline Variable & $\begin{array}{l}\text { Variable in } \\
\text { actual units }\end{array}$ & Levels* & Sum & Mean & SS & \% SST & Sum & Mean & SS & \% SST \\
\hline & & & \multicolumn{4}{|c|}{ Lovastatin } & \multicolumn{4}{|c|}{ Biomass } \\
\hline \multirow[b]{2}{*}{ A } & \multirow{2}{*}{ Glucose, $\mathrm{g} / \mathrm{l}$} & $1(=5)$ & 8.4173 & 1.4029 & \multirow{2}{*}{0.357} & \multirow{2}{*}{3.03} & 62.937 & 10.4895 & \multirow{2}{*}{70.2252} & \multirow{2}{*}{20.92} \\
\hline & & $2(=40)$ & 10.4872 & 1.7479 & & & 91.9663 & 15.3277 & & \\
\hline \multirow{2}{*}{ B } & \multirow{2}{*}{$\mathrm{NH}_{4} \mathrm{Cl}, \mathrm{g} / \mathrm{l}$} & $1(=1)$ & 11.7966 & 1.9661 & \multirow{2}{*}{1.8319} & \multirow{2}{*}{15.52} & 55.9728 & 9.3288 & \multirow{2}{*}{153.78} & \multirow{2}{*}{45.82} \\
\hline & & $2(=5)$ & 7.108 & 1.1847 & & & 98.9305 & 16.4884 & & \\
\hline \multirow{2}{*}{ C } & \multirow{2}{*}{$\mathrm{KH}_{2} \mathrm{PO}_{4}, \mathrm{~g} / \mathrm{l}$} & $1(=1)$ & 7.3391 & 1.2232 & \multirow{2}{*}{1.4886} & \multirow{2}{*}{12.61} & 64.077 & 10.6795 & \multirow{2}{*}{59.6273} & \multirow{2}{*}{17.77} \\
\hline & & $2(=4)$ & 11.5655 & 1.9276 & & & 90.8263 & 15.1377 & & \\
\hline \multirow{2}{*}{ D } & \multirow{2}{*}{$\mathrm{MgSO}_{4}, \mathrm{~g} / \mathrm{l}$} & $1(=0.098)$ & 11.8636 & 1.9773 & \multirow{2}{*}{1.9382} & \multirow{2}{*}{16.42} & 77.2709 & 12.8785 & \multirow{2}{*}{0.0109} & \multirow{2}{*}{0.003} \\
\hline & & $2(=0.98)$ & 7.041 & 1.1735 & & & 77.6325 & 12.9387 & & \\
\hline \multirow[t]{2}{*}{$\mathrm{E}$} & \multirow{2}{*}{$\mathrm{MnSO}_{4}, \mathrm{~g} / \mathrm{l}$} & $1(=0)$ & 6.9031 & 1.1505 & \multirow{2}{*}{2.1661} & \multirow{2}{*}{18.35} & 86.6889 & 14.4482 & \multirow{2}{*}{28.4424} & \multirow{2}{*}{8.47} \\
\hline & & $2(=0.447)$ & 12.0015 & 2.0002 & & & 68.2144 & 11.3691 & & \\
\hline \multirow{2}{*}{$\mathbf{F}$} & \multirow{2}{*}{$\mathrm{pH}$ initial } & $1(=3)$ & 9.5513 & 1.5919 & \multirow{2}{*}{0.0033} & 0.03 & 77.7463 & 12.9577 & 0.0289 & 001 \\
\hline & & $2(=6)$ & 9.3533 & 1.5589 & & 0.03 & 77.1571 & 12.8595 & 0.0209 & 0.01 \\
\hline G & Shaker speed, & $1(=110)$ & 11.9299 & 1.9883 & 62 & 4 & 72.1048 & 12.0175 & 95296 & 284 \\
\hline & rpm & $2(=150)$ & 6.9747 & 1.1624 & 2.0402 & 11 & 82.7985 & 13.7998 & 9.0270 & 2.04 \\
\hline H & Temperature, 'o' & $1(=25)$ & 11.8844 & 1.9807 & & & 83.9293 & 13.9882 & 364 & 4.17 \\
\hline$\Pi$ & Temper adure, & $2(=35)$ & 7.0201 & 1.17 & 1.9710 & 10.11 & 70.9741 & 11.829 & 9004 & 4.11 \\
\hline
\end{tabular}

SS- sum of squares, SST- total sum of squares. Parentheses indicate actual value of the variable

temperature were significant for the production of lovastatin at their lower level (fig. 4A and Table 3). The initial $\mathrm{pH}$ did not influence much on the production of lovastatin at both the levels.

Contour plots were drawn between the production of lovastatin and influencing parameters. Fig. 4B showed the combined effect of agitation rate and $\mathrm{MnSO}_{4}$ on the production of lovastatin, where the production of lovastatin was high, when the agitation speed and $\mathrm{MnSO}_{4}$ were at lower and higher levels, respectively. Similarly, fig. 4C showed the effect of $\mathrm{MgSO}_{4}$ and agitation speed on the production of lovastatin; both factors are significant at their low levels. Effect of physical parameters, such as, agitation speed and temperature on the production of lovastatin has been explained in fig. 4D and were significant at their lower level. Similarly, $\mathrm{MgSO}_{4}$ (at lower level) and $\mathrm{MnSO}_{4}$ (at higher level) were influenced on the production of lovastatin (fig. 4E). The curvature in the contour plot indicates that there was possible interaction between the parameters otherwise it should give a straight flat surface.

At higher agitation rate, the production of lovastatin was observed to be low, which might be due to the shear sensitivity of the organism. Shear sensitiveness of Aspergillus sp. was reported and it drastically reduced the production of lovastatin ${ }^{[48,49]}$. Similarly, Barrios-González et al. ${ }^{[50]}$ reported that Monascus sp. has produced high amount of lovastatin in the solid- state fermentation than in the submerged fermentation. However, it is interesting to note that, at higher agitation speed, the production of biomass was high. Hence, the drop in the production of lovastatin at high agitation is not associated with shear sensitivity of the cells; rather it could be associated with dissolved oxygen level of the medium. Since, agitation rate was linked with the mass transfer of substrate, product and dissolved oxygen level. In the biosynthesis of lovastatin, the oxidation of monacolin $\mathrm{L}$ led to monacolin $\mathrm{J}$, one of the intermediates in the biosynthesis pathway of lovastatin ${ }^{[1,51]}$. More amount of dissolved oxygen might lead to high accumulation of intermediates that could reduce the production of final product, lovastatin. At high agitation rate, there could be more chances that the organism can self-regulate its production of lovastatin. Since the contact between the cell and product, lovastatin was inevitable due to the high mass transfer rate. Since, lovastatin was observed to inhibit its own synthesis as reported by López et al. ${ }^{[46]}$ and Jia et al. ${ }^{[52]}$. These could be probable reasons for lower production of lovastatin at high agitation speed.

Moreover, the production of lovastatin was observed to be high at its lower temperature level $\left(25^{\circ}\right)$. Tsukahara et al. ${ }^{[53]}$ reported a 30 -fold increase in the production of lovastatin without citrinin when there was a shift in the temperature from $30^{\circ}$ to $23^{\circ}$. The above results showed a strong thermodynamically favourable condition towards the production of lovastatin at lower temperature. 


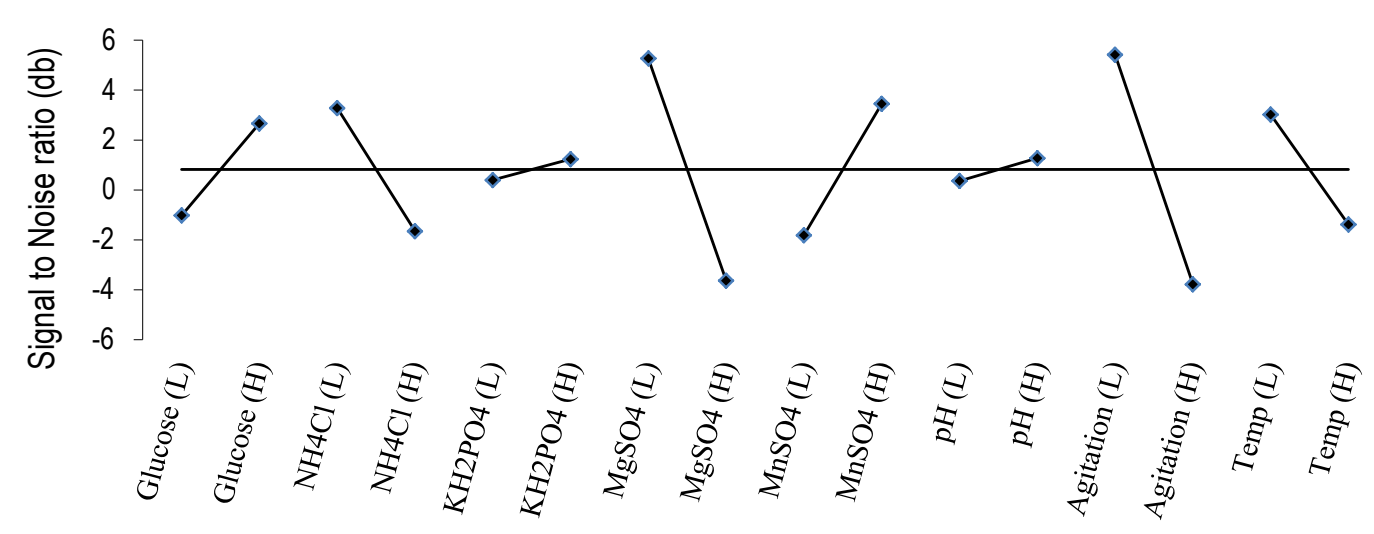

Factors and their levels

$\mathrm{B}$

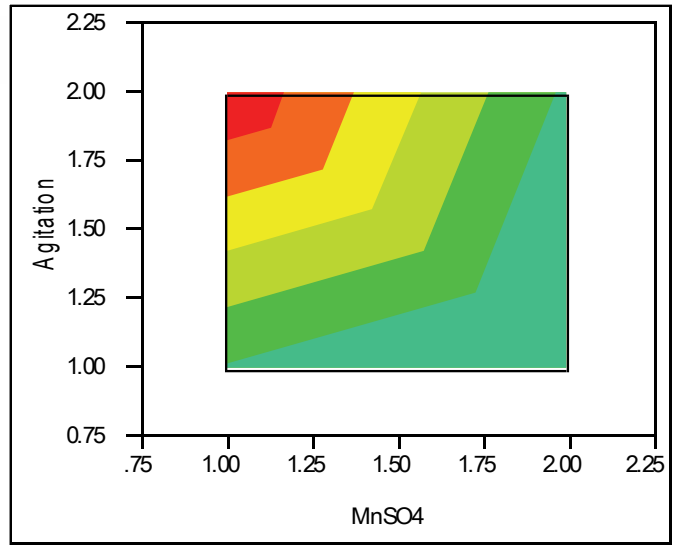

D

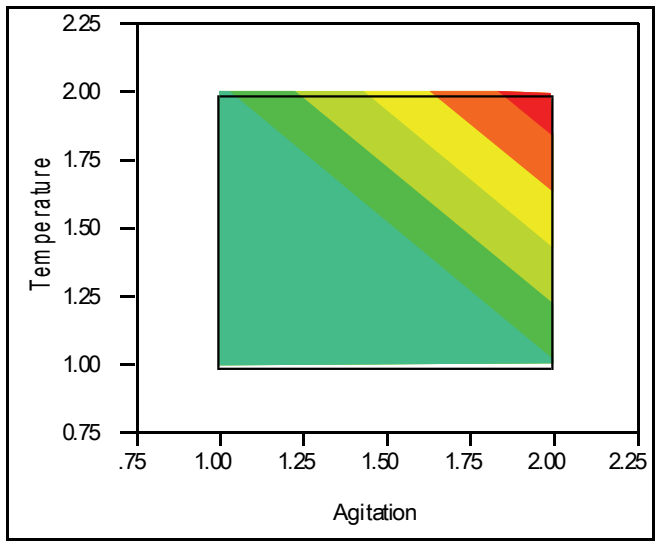

C

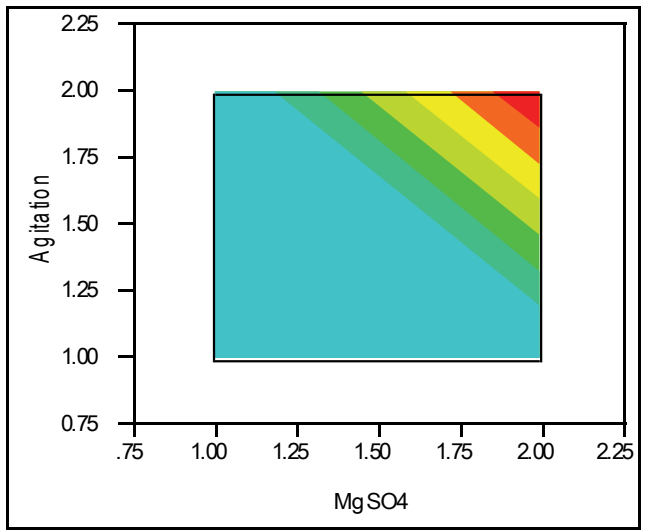

E

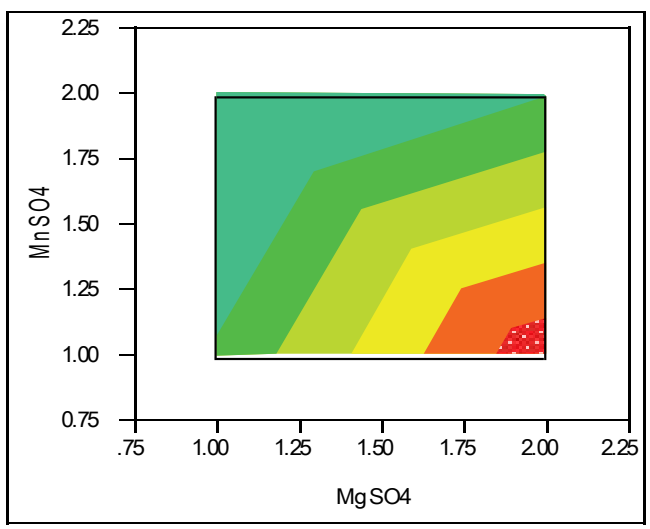

Fig. 4: The main effect plot for the production of lovastatin

Relative influence of both physical and chemical parameters on the production of lovastatin is represented at their lower (L) and higher $(\mathrm{H})$ levels. Contour plots (B-E) shows the combined effect of significant parameters $\left(\mathrm{MnSO}_{4}, \mathrm{MgSO}_{4}\right.$, temperature and agitation) on the production of lovastatin. Lovaststin $(\mathrm{mg} / \mathrm{l}): \square=0.750 ;=1.000 ;=0.750 ;=1.500 ;=1.750 ; \square>1.750$

More quantitatively, the effect of each parameter on the production of lovastatin can be accurately estimated using the Phadke method ${ }^{[32,54]}$ as given in Table 3. Difference in the sum of production of lovastatin between low and high levels of $\mathrm{MnSO}_{4}$ was higher than other chemical parameters, whose contribution (i.e., total sum of square) was $18.35 \%$. Similarly, the difference in the sum of production of lovastatin between low and high levels of $\mathrm{MgSO}_{4}$ and $\mathrm{NH}_{4} \mathrm{Cl}$ were also high. The total sum of square of $\mathrm{MgSO}_{4}$ 
and $\mathrm{NH}_{4} \mathrm{Cl}$ were 16.42 and 15.52 , respectively. If the difference of the sum of lovastatin production between the levels is very low, it indicates the relative influence of the parameter on the production of lovastatin is insignificant. It was observed for the case of glucose and initial $\mathrm{pH}$ ( $\mathrm{SST}<3 \%$ ). The levels of significance of both physical and chemical factors on the production of lovastatin are represented in the Pareto plot (fig. 5). It showed that among the physical and chemical parameters, $\mathrm{MnSO}_{4}$ (at higher level) and agitation speed (at lower level) had showed the maximum contribution towards the production of lovastatin. It also showed that physical parameters were contributed significantly to the production of lovastatin as equally as that of chemical parameters, except initial $\mathrm{pH}$. This showed that there are more scope and necessitates to incorporate physical parameters in the further process development of lovastatin. Similar results were observed by Dasu et $a{ }^{\left[{ }^{[32]}\right.}$ for the production of griseofulvin production by $P$. griseofulvum MTCC 1898 where, they also have emphasized the contribution of physical parameters, such as, $\mathrm{pH}$, agitation, and aeration on the production of griseofulvin. Those physical parameters have showed a maximum contribution on the production of griseofulvin than that of chemical parameters in batch reactor experiments.

The ANOVA analysis also showed the significance of $\mathrm{MnSO}_{4}, \mathrm{MgSO}_{4}$, agitation speed, and temperature on the production of lovastatin with more than $75 \%$ confidence $(\mathrm{p}<0.25)$. Dikshit and Tallapragada ${ }^{[55]}$ have also showed the production of lovastatin by Monascus sp. was highly influenced by $\mathrm{MgSO}_{4}$ out of the screened variables. Further, the current results were close to the experimental observation of Sayyed et al. ${ }^{[2]}$ and have showed the interaction among the chemical parameters. Chung et al..$^{[23]}$ has also employed the Taguchi's orthogonal array method for the finding the optimal chemical composition for the maximum production of lovastatin. They have observed that whole wheat flour $(1 \%)$, peptone $(1 \%)$, soy bean $(0.01 \%)$, and $\mathrm{KH}_{2} \mathrm{PO}_{4}$ for the production of monacolin $\mathrm{K}$.

The maximum biomass concentration of $20.95 \mathrm{~g} / \mathrm{l}$ was observed for the experimental run 10, whose composition was (in g/l): glucose- 40; $\mathrm{NH}_{4} \mathrm{Cl}-\mathrm{5}$; $\mathrm{KH}_{2} \mathrm{PO}_{4^{-}}$4; $\mathrm{MgSO}_{4^{-}}$0.098. The least biomass concentration was observed with experimental run 9 (Table 1). The selected physical and medium constituents showed a significant contribution to the growth of cells (Table 3 ) as also observed from main effect plot (fig. 6A). From the main effect plot, it could be observed that $\mathrm{NH}_{4} \mathrm{Cl}$ (nitrogen source), glucose (carbon source), and $\mathrm{KH}_{2} \mathrm{PO}_{4}$ (phosphorous source) were the most significant parameters for the growth of the cell. In physical parameters, agitation speed and temperature are the significant parameters. Fig. 6B demonstrated the combined effect of nitrogen source and carbon source on the production of cell mass. The biomass was found to be increased with the increase in the concentration of glucose and $\mathrm{NH}_{4} \mathrm{Cl}$. Similar trend was also observed for the phosphorous sources. The contour plot (fig. 6C) showed the production of cell mass as a response by varying the carbon (glucose) and phosphorous $\left(\mathrm{KH}_{2} \mathrm{PO}_{4}\right)$ sources. Both parameters were significant on the cell mass formation at their high level. The same trend was observed for the production of cell mass on varying phosphorous and nitrogen sources (fig. $6 \mathrm{D})$. Interestingly, the production of biomass dropped at low agitation speed and high level of temperature (fig. 6E). The agitation rate was linked with numbers of pellet formation. In high-agitated system, the number of pellet formation was high, which could be probable reason for the better biomass at high agitation speed.

The relative significance of these parameters can also be found from the percentage of sum of squares values for the production of biomass (Table 3 ). The nitrogen $\left(\mathrm{NH}_{4} \mathrm{Cl}\right)$ source contributed more when compared

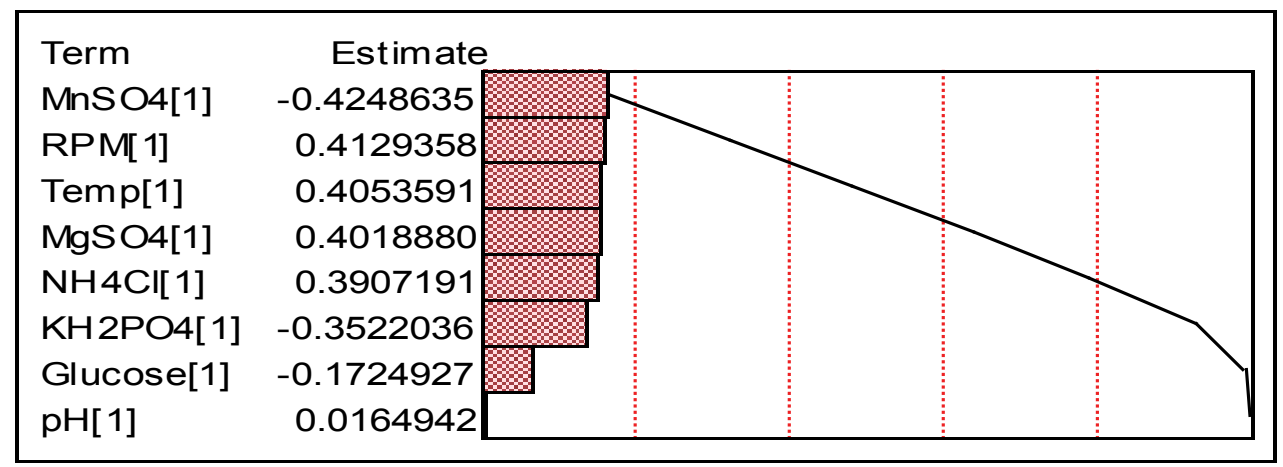

Fig. 5: Pareto chart for significant parameters for the production of lovastatin 
A

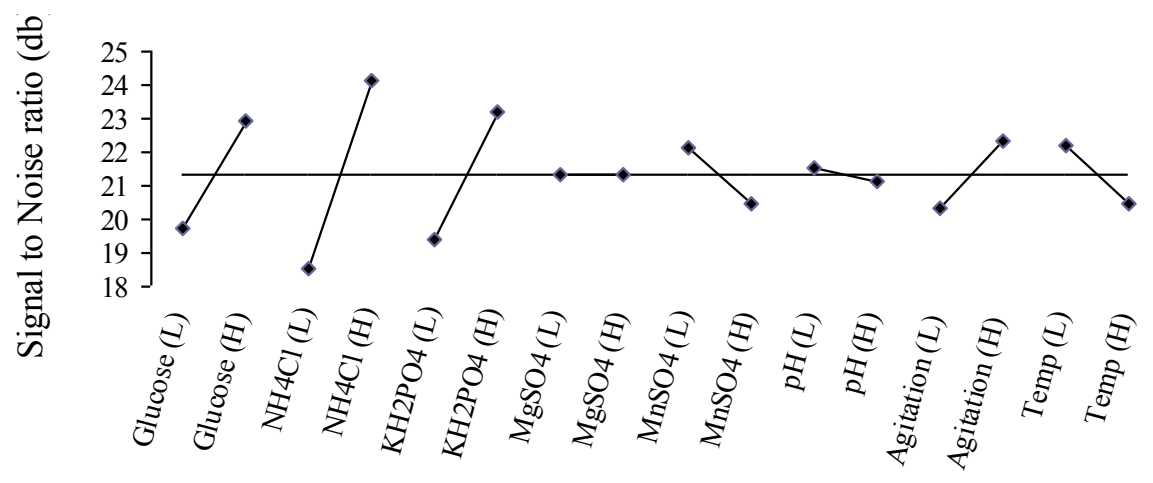

Factors and their levels

B

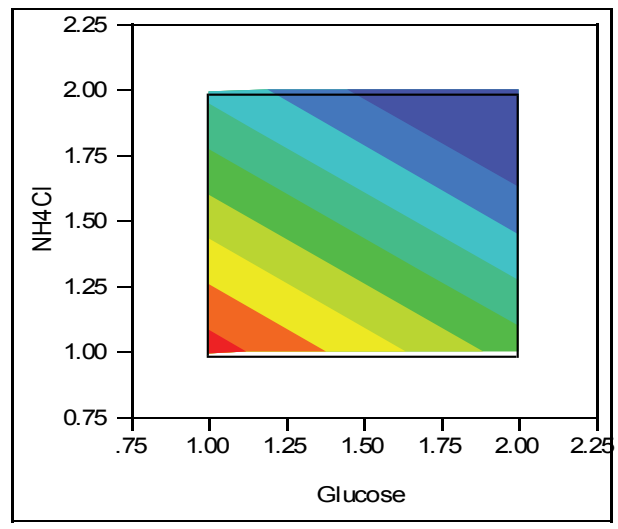

D

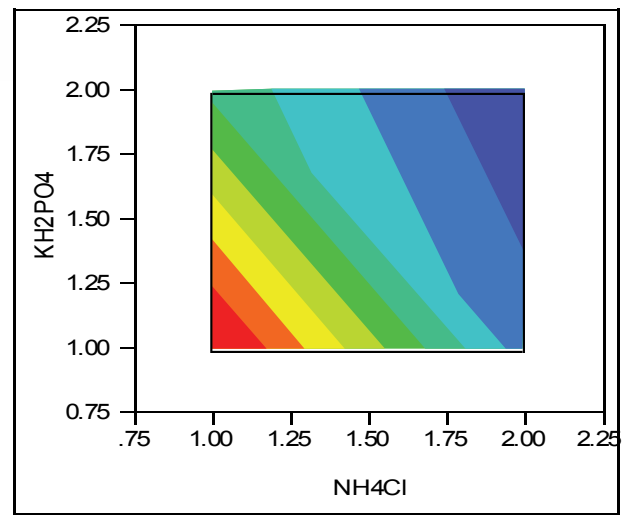

C

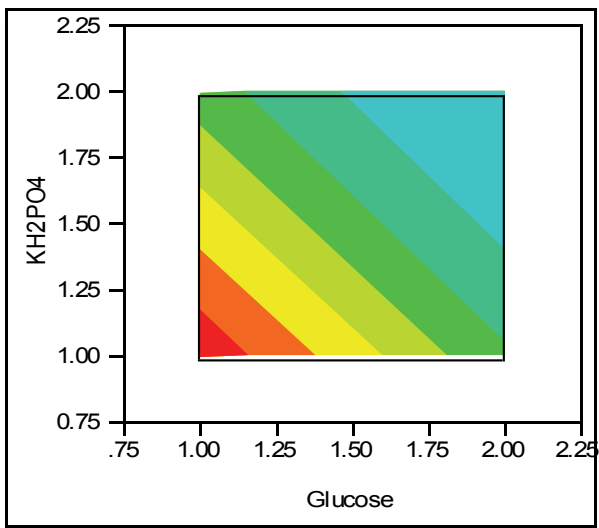

E

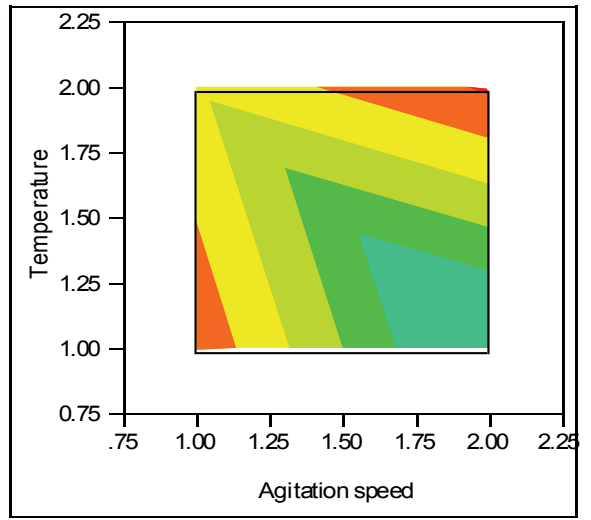

Fig. 6: The main effect plot for the growth of cell

Relative influence of both physical and chemical parameters on the production of biomass is represented at lower ( $L$ ) and higher (H) levels. Contour plots (B-E) shows the combined effect of significant parameters $\left(\mathrm{NH}_{4} \mathrm{Cl}\right.$, glucose, $\mathrm{KH}_{2} \mathrm{PO}_{4}$, temperature and agitation) on the growth of cells. Lovaststin $(\mathrm{mg} / \mathrm{l}):=0.750 / 0.875 / 11 ; \square=0.875 / 10 / 12 ;=10 / 11.25 / 13 ;=11.25 / 12.5 / 14 ;$ $=12.5 / 13.7515 ;=13.75 / 15 ;=15 ;=16.25 ; \square>16.25$

to carbon and phosphate source to the growth of the cell. Glucose, $\mathrm{NH}_{4} \mathrm{Cl}$ and $\mathrm{KH}_{2} \mathrm{PO}_{4}$ had the relative contribution of $20.92,45.82$, and $17.77 \%$, respectively (Table 3). Chung et al. ${ }^{[23]}$ have also revealed that $\mathrm{KH}_{2} \mathrm{PO}_{4}$ was a significant parameter for the growth of Monascus sp. The agitation and temperature had a relatively low significance on the cell growth. Moreover, initial $\mathrm{pH}$ and $\mathrm{MgSO}_{4}$ were insignificant variables for the cell growth compared to other factors irrespective of their levels. The Pareto diagram showed the relative significance of these parameters for the production of biomass (fig. 7). The least contributing factor is $\mathrm{MgSO}_{4}$, whose percentage of sum of square is less than $0.003 \%$.

The difference in the production of biomass between the lower and higher levels of physical parameters is relatively insignificant (Table 3). Hence, compared to the physical parameters, the contribution of chemical 


\begin{tabular}{|lll|l|l|}
\hline Term & Estimate \\
$\mathrm{NH} 4 \mathrm{Cl}[1]$ & -3.579803 \\
$\mathrm{Glucose}[1]$ & -2.419111 \\
$\mathrm{KH} 2 \mathrm{PO} 4[1]$ & -2.229112 \\
$\mathrm{MnSO} 4[1]$ & 1.539546 \\
Temp[1] & 1.079599 \\
$\mathrm{RPM}[1]$ & -0.891143 \\
$\mathrm{pH}[1]$ & 0.049102 \\
$\mathrm{MgSO} 4[1]$ & -0.030132
\end{tabular}

Fig. 7: Pareto chart for significant parameters for the production of cell mass

parameters was relatively more significant. It just opposite of the results obtained for the production of lovastatin. Especially, $\mathrm{NH}_{4} \mathrm{Cl}$ is the most significant parameter in the production of biomass at its higher level, whereas, it is the least significant parameter among the significant parameters at its lower level for the production of lovastatin (Table 3 and figs. 4 and 6). In contrast, $\mathrm{MgSO}_{4}$ is the one of the significant parameters in the production of lovastatin, whereas, the same was insignificant on the production of cell mass. It showed the strong role of $\mathrm{MgSO}_{4}$ (at low level) in the biosynthesis pathway of lovastatin. Interestingly, parameters and their relative influences were observed inversely between the production of lovastatin and cell growth, which strongly ascertains the condition of growth limitation favoured the production of secondary metabolite, lovastatin.

Chemical parameters, such as, glucose, ammonium chloride, potassium dihydrogen phosphate, had showed a high level of significance with more than $99 \%$ confidence $(\mathrm{p}<0.01)$. Similarly, $\mathrm{MnSO}_{4}$ is also another significant compound with $97 \%$ confidence.

There was a significant variation in the morphology and localization pattern of lovastatin in M. purpureus when the culture condition changed. However, there was no considerable variation in the production profiles of lovastatin among the culture conditions. It has seen that the maximum localization of lovastatin was observed outside the cell in the case of dynamic or agitated culture. Hence, M. purpureus has to be grown on dynamic modes of fermentation to have simple downstream processing for large scale operations. The Taguchi's robust experimental design has been adopted to find the relative significance of both physical and chemical parameters. On comparison with the chemical parameters, the physical parameters, viz., agitation rate and temperature, have also been found equally significant on the production of lovastatin.
These results again corroborated the importance of physical parameters on the production of lovastatin, which needs to be given special attention in the future process development. Chemical parameters were more significant for the production of cell mass compared to physical parameters. By the Taguchi's orthogonal method, the optimal conditions for the production of lovastatin and growth of $M$. purpureus have been established. However, there was a significant interaction between the parameters as observed from the non-linearity of response in contour diagram. The current finding may be nearest to the optimal value based on the range selected.

\section{Acknowledgements:}

The authors gratefully acknowledge the help rendered by Dr. V. Kesavan, members of Chemical Biology Laboratory, Mr. Z. Aslam Basha, and Mr. N. Arumugam of the Department of Biotechnology, IIT Madras and members of Biochemical Engineering Laboratory of the Department of Chemical Engineering, IIT Madras during the different stages of this work.

\section{Conflicts of interest:}

There are no conflicts of interest.

\section{Financial support and sponsorship:}

Nil.

\section{REFERENCES}

1. Seenivasan A, Subhagar S, Aravindan R, Viruthagiri T. Microbial production and biomedical applications of lovastatin. Indian J Pharm Sci 2008;70:701-9.

2. Panda T, Amrutha Devi V. Regulation and degradation of HMG-CoA reductase. Appl Microbiol Biotechnol 2004;66:143-52.

3. Alberts AW. Discovery, biochemistry and biology of lovastatin. Am J Cardiol 1988;62:10J-5J.

4. Subhan M, Faryal R, Macreadie I. Exploitation of Aspergillus 
terreus for the production of natural statins. J Fungi 2016;2(2):13.

5. Merx MW, Weber C. Benefits of statins beyond lipid lowering. Drug Discov Today Dis Mech 2008;5:3-4.

6. Xie X, Watanabe K, Wojcicki WA, Wang CC, Tang Y. Biosynthesis of lovastatin analogs with a broadly specific acyltransferase. Chem Biol 2006;13:1161-9.

7. Xie X, Tang Y. Efficient Synthesis of Simvastatin by Use of Whole-Cell Biocatalysis. Appl Environ Microbiol 2007;73:2054-60.

8. Zhuge B, Fang HY, Yu H, Rao ZM, Shen W, Song J, Zhuge J. Bioconversion of lovastatin to a novel statin by Amycolatopsis sp. Appl Microbiol Biotechnol 2008;79:209-16.

9. Seenivasan A, Panda T, Théodore T. Characterization, Modes of Synthesis, and Pleiotropic Effects of Hypocholesterolemic Compounds-A Review. Open Enzym Inhib J 2011;4:23-32.

10. Endo A, Hasumi K, Yamada A, Shimoda R, Takeshima H. The synthesis of compactin (ML-236B) and monacolin K in fungi. J Antibiot (Tokyo)1986;39:1609-10.

11. Manabe M. Fermented foods and mycotoxins. Mycotoxins 2001;51:25-8.

12. Bennett JW, Klich M. Mycotoxins. Clin Microbiol Rev 2003;16(3):497-516.

13. Su YC, Wang JJ, Lin TT, Pan TM. Production of the secondary metabolites $\gamma$-aminobutyric acid and monacolin $\mathrm{K}$ by Monascus. J Ind Microbiol Biotechnol 2003;30:41-6.

14. Li YG, Zhang F, Wang ZT, Hu ZB. Identification and chemical profiling of monacolins in red yeast rice using high-performance liquid chromatography with photodiode array detector and mass spectrometry. J Pharm Biomed Anal 2004;35:1101-12.

15. Nguyen T, Karl M, Santini A. Red Yeast Rice. Foods 2017;6(3):19.

16. Dikshit R, Tallapragada P. Comparative study of Monascus sanguineus and its albino mutant based on molecular and chemical profiling. Food Biotechnol 2017;31(1):42-56.

17. Rahayu YY, Yoshizaki Y, Yamaguchi K, Okutsu K, Futagami $\mathrm{T}$, Tamaki H, et al. Key volatile compounds in red koji-shochu, a Monascus-fermented product, and their formation steps during fermentation. Food Chemistry 2017;224:398-406.

18. Manzoni M, Bergomi S, Rollini M, Cavazzoni V. Production of statins by filamentous fungi. Biotechnol Lett 1999;21:253-7.

19. Miyake T, Mori A, Kii T, Okuno T, Usui Y, Sato F, et al. Light effects on cell development and secondary metabolism in Monascus. J Ind Microbiol Biotechnol 2005;32:103-8.

20. Endo A. Monacolin K, a new hypocholesterolemic agent produced by a Monascus species. J Antibiot (Tokyo) 1979;32:852-4.

21. Chang YN, Huang JC, Lee CC, Shih L, Tzeng YM. Use of response surface methodology to optimize culture medium for production of lovastatin by Monascus ruber. Enzyme Microb Technol 2002;30:889-94.

22. Sayyed SA, Panda BP, Javed S, Ali M. Optimization of nutrient parameters for lovastatin production by Monascus purpureus MTCC 369 under submerged fermentation using response surface methodology. Appl Microbiol Biotechnol 2007;73(5):1054-8.

23. Chung CC, Chen HH, Hsieh PC. Application of the Taguchi method to optimize Monascus spp. culture. J Food Process Eng 2007;30:241-54.
24. Mulder KC, Mulinari F, Franco OL, Soares MS, Magalhães BS, Parachin NS. Lovastatin production: From molecular basis to industrial process optimization. Biotechnol Adv 2015;33(6):648-65.

25. Panda BP, Javed S, Ali M. Optimization of fermentation parameters for higher lovastatin production in red mold rice through co-culture of Monascus purpureus and Monascus ruber. Food Bioprocess Technol 2010;3:373-8.

26. Feng Y, Shao Y, Zhou Y, Chen F. Effects of glycerol on pigments and monacolin $\mathrm{K}$ production by the high-monacolin K-producing but citrinin-free strain, Monascus pilosus MS-1. Eur Food Res Technol 2015;240(3):635-43.

27. Dikshit R, Tallapragada P. Statistical optimization of lovastatin and confirmation of nonexistence of citrinin under solid-state fermentation by Monascus sanguineus. J Food Drug Anal 2016;24:433-40.

28. Lopez JC, Pérez JS, Sevilla JF, Fernandez FA, Grima EM, Chisti Y. Production of lovastatin by Aspergillus terreus: effects of the $\mathrm{C}$ : $\mathrm{N}$ ratio and the principal nutrients on growth and metabolite production. Enzyme Microb Technol 2003;33(2):270-7.

29. Yang DJ, Hwang LS. Study on the conversion of three natural statins from lactone forms to their corresponding hydroxy acid forms and their determination in Pu-Erh tea. J Chromatogr A 2006;1119(1):277-84.

30. Seenivasan A, Panda T, Théodore T. Lovastatin nanoparticle synthesis and characterization for better drug delivery. Open Biotechnol J 2011;5(1):28-32.

31. Panda T, Babu PSR, Kumari JA, Rao DS, Theodore K, Jagannandha Rao K, et al. Review: Bioprocess Optimizationa Challenge. J Microbiol Biotechnol 1997;7:367-72.

32. Dasu VV, Panda T, Chidambaram M. Determination of significant parameters for improved griseofulvin production in a batch bioreactor by Taguchi's method. Process Biochem 2003;38:877-80.

33. Gündoğdu KT, Deniz İ, Çalışkan G, Şahin ES, Azbar N. Experimental design methods for bioengineering applications. Criti Rev Biotechnol 2016;36(2):368-88.

34. Taguchi G. Introduction to quality engineering: designing quality into products and processes. Dearborn, Michigan: Asian Productivity Organization; 1986.

35. Khuri AI, Mukhopadhyay S. Response surface methodology. WIREs Comp Stat 2010;2:28-149.

36. Singh V, Haque S, Niwas R, Srivastava A, Pasupuleti M, Tripathi CK. Strategies for fermentation medium optimization: an in-depth review. Front Microbiol 2016;7:2087.

37. Han JJ, Yang TH, Rhee JS. Optimization of reaction variables for sucrose monoester production using lipase in a solvent free system by Taguchi's method. Biotechnol Tech 1998;12:295-9.

38. Mrvčić J, Stanzer D, Stehlik-Tomas V, Škevin D, Grba S. Optimization of bioprocess for production of copperenriched biomass of industrially important microorganism Saccharomyces cerevisiae. J Biosci Bioeng 2007;103:331-7.

39. Hwang CF, Chang JH, Houng JY, Tsai CC, Lin CK, Tsen HY. Optimization of medium composition for improving biomass production of Lactobacillus plantarum Pi06 using the Taguchi array design and the Box-Behnken method. Biotechnol Bioprocess Eng 2012; 17:827-34.

40. Seenivasan A, Gummadi SN, Panda T, Théodore T. Quantification of lovastatin produced by Monascus purpureus. Open Biotechnol J 2015;9(1):6-13. 
41. Byrne DM, Taguchi S. The Taguchi approach to parameter design. Qual Prog 1987;20:19-26.

42. Hamdi M, Blanc PJ, Goma G. Effect of aeration conditions on the production of red pigments by Monascus purpureus growth on prickly pear juice. Process Biochem 1996;31:543-7.

43. Musaalbakri AM, Ariff A, Rosfarizan M, Ismail AK. Kinetics of red pigment fermentation in 2-litre stirred tank fermenter using different types and concentrations of carbon sources. J Trop Agric Food Sci 2007;35(2):287-96.

44. Jemal M, Xia YQ. Bioanalytical method validation design for the simultaneous quantitation of analytes that may undergo interconversion during analysis. J Pharm Biomed Anal 2000;22:813-27.

45. Huang $\mathrm{Z}, \mathrm{Xu} \mathrm{Y}, \mathrm{Li} \mathrm{Y}$, Wang Y. Conversion investigation for lovastatin and its derivatives by HPLC. J Chromatogr Sci 2010;48:631-6.

46. López JLC, Rodríguez PEM, Ferrón VMA, Pérez SJA, Fernández Sevilla JM, Chisti Y. Lovastatin inhibits its own synthesis in Aspergillus terreus. J Ind Microbiol Biotechnol 2004;31(1):48-50.

47. Porcel EMR, López CJL, Perez SJA, Chisti Y. Enhanced production of lovastatin in a bubble column by Aspergillus terreus using a two-stage feeding strategy. J Chem Technol Biotechnol 2007;82(1):58-64.

48. Porcel ER, López JC, Pérez JS, Sevilla JF, Chisti Y. Effects of pellet morphology on broth rheology in fermentations of Aspergillus terreus. Biochem Eng J 2005;26(2):139-44.
49. López JC, Pérez JS, Sevilla JF, Porcel ER, Chisti Y. Pellet morphology, culture rheology and lovastatin production in cultures of Aspergillus terreus. J Biotechnol 2005;116(1):61-77.

50. Barrios-González J, Baños JG, Covarrubias AA, Garay-Arroyo A. Lovastatin biosynthetic genes of Aspergillus terreus are expressed differentially in solid-state and in liquid submerged fermentation. Appl Microbiol Biotechnol 2008;79(2):179-86.

51. Barriuso J, Nguyen DT, Li JW, Roberts JN, MacNevin $\mathrm{G}$, Chaytor JL, et al. Double oxidation of the cyclic nonaketide dihydromonacolin $\mathrm{L}$ to monacolin $\mathrm{J}$ by a single cytochrome P450 monooxygenase, Lov A. J Am Chem Soc 2011;133(21):8078-81.

52. Jia ZH, Zhang XL, Zhao YL, Cao XJ. Enhancement of lovastatin production by supplementing polyketides antibiotics to the submerged culture of Aspergillus terreus. Appl Biochem Biotechnol 2010;160:2014-25.

53. Tsukahara M, Shinzato N, Tamaki Y, Namihira T, Matsui T. Red yeast rice fermentation by selected Monascus sp. with deep-red color, lovastatin production but no citrinin, and effect of temperature-shift cultivation on lovastatin production. Appl Biochem Biotechnol 2009;158(2):476-82.

54. Phadke MS. Quality engineering using robust design. Upper Saddle River, New Jersey; Prentice Hall: 1989.

55. Dikshit R, Tallapragada P. Bio-synthesis and screening of nutrients for lovastatin by Monascus sp. under solid-state fermentation. J Food Sci Technol 2015;52(10):6679-86. 